\title{
ANALISIS KEBERLANJUTAN PENGELOLAAN EKOWISATA EKOSISTEM HUTAN RAWA GAMBUT PADA KAWASAN TAMAN WISATA ALAM BANING
}

\author{
Antonius \\ Fakultas Pertanian Universitas Kapuas Sintang \\ email: anton1975_gurung@yahoo.co.id
}

\begin{abstract}
ABSTRAK
Abstrak : Kawasan Taman Wisata Alam Baning merupakan ekosistem hutan rawa gambut yang tergolong rapuh, sehingga diperlukan pengelolaan yang penuh kehati-hatian. Sebagai kawasan konservasi, Taman Wisata Alam Baning mengalami permasalahan karena tekanan masyarakat sekitar, seperti penyerobotan kawasan dan pembuatan kanal/parit sekeliling kawasan. Terganggunya fungsi ekologis berimplikasi pada aspek sosial ekonomis karena menurunnya daya tarik kawasan sebagai objek wisata, sehingga diperlukan penanganan secara kelembagaan. Studi ini dilakukan untuk menganalisis status dan indeks keberlanjutan pengelolaan Taman Wisata Alam Baning berdasarkan dimensi sosial ekonomi, ekologi dan institusional/kelembagaan. Analisis menggunakan metode Multi Dimensional Scaling (MDS). Tujuan kedua adalah untuk menganalisis atribut yang mempengaruhi sensitivas indeks dan keberlanjutan status leverage. Hasil penelitian menunjukkan bahwa analisis dimensi sosial ekonomi, ekologi dan institusional/kelembagaan cukup berkelanjutan yakni berturut-turut sebesar 55,08\%; 73,12\% dan 51,42\%.
\end{abstract}

Kata kunci: Indeks keberlanjutan, status keberlanjutan,atribut sensitivas

\section{PENDAHULUAN}

Taman Wisata Alam Baning merupakan ekosistem hutan rawa gambut yang terletak di jantung kota Sintang. TWA. Baning ditunjuk sebagai kawasan Taman Wisata Alam melalui Surat Keputusan Menteri SK Menteri Kehutanan dan Perkebunan Nomor: 405 /kptsII/1999 pada tanggal 14 Juni 1999 dengan luas 213 Ha. Secara administratif kawasan ini terletak di desa Baning Kota, Desa Sungai Ana, Kelurahan Tanjungpuri, Kelurahan Akcaya Satu dalam wilayah Kecamatan Sintang Kabupaten Sintang, Provinsi Kalimantan Barat dan secara geografis terletak pada $1^{\circ}$ $03^{\prime}-1^{\circ} 16^{\prime}$ Lintang Selatan dan $110^{\circ}$ 037' - 113º 37' Bujur Timur.

Taman Wisata Alam Baning memiliki peran strategis dilihat dari berbagi aspek, antara lain: aspek ekologis sebagai reservoir alami 
limpasan air hujan yang masuk dari daerah tangkapan air dari sungai Melawi dan sungai Kapuas sehingga berfungsi sebagai pengendali banjir, sebagai ruang terbuka hijau kota Sintang, pengembangan wisata alam, mengandung biodiversity untuk laboratorium alami dan sebagai sumber plasma nutfah.

Dilaporkan oleh Balai Konservasi Sumberdaya Alam Kalimantan Barat bahwa kawasan Taman Wisata Alam Baning yang merupakan ekosistem hutan rawa gambut dengan ketebalan gambut yang bervariasi terus mengalami penurunan kualitas, ditandai dengan turunnya permukaan gambut, perakaran pohon menggantung yang akhirnya pohon-pohon besar banyak yang tumbang karena kehilangan daya cengkram pada tanah gambut yang mengalami subsiden.

Penurunan permukaan gambut disebabkan oleh kemampuan menahan air semakin berkurang seiring dengan dibangunnya kanal oleh pemerintah daerah tanpa adanya koordinasi yang baik dengan pihak Konservasi Sumber Daya Alam
Kalimantan Barat sebagai pemangku kawasan. Pembangunan kanal telah mengakibatkan air mengalir keluar dari kawasan gambut. Keberlangsungan ekosistem gambut tergantung kepada kemampuan gambut untuk menyimpan air dan selalu dalam kondisi basah. Bila gambut mengalami kekeringan maka akan mudah terbakar, mengalami oksidasi dan mempercepat proses kematangan tanah gambut akibatnya permukaan gambut turun (Agus dan Subiksa, 2008). Selain itu, padatnya penduduk di sekitar kawasan mengakibatkan kawasan terus mengalami penyerobotan dan pencurian beberapa tumbuhan dan satwa di dalamnya.

Uraian tersebut memberikan tafsiran bahwa kebijakan pengelolaan sumberdaya alam yang integral masih kurang serius. Pembangunan berlangsung secara sektoral yaitu untuk memenuhi tujuan tertentu dan mengabaikan aspek keterpaduan yang berkelanjutan. Implikasinya terjadi tumpang tindih kewenangan yang bermuara pada pengelolaan sumberdaya alam yang tidak efektif dan efisien. Kerusakan lingkungan di 
Indonesia termasuk ekosistem gambut sebagai bentuk dari perencanaan pembangunan yang berorientasi fisik dari pada faktor keseimbangan lingkungan. Salah satu masalah mendasar dari kerusakan ekosistem gambut di Taman Wisata Alam Baning ialah kebijakan pengelolaan yang belum sepenuhnya berorientasi pada konservasi dan lemahnya koordinasi antar instansi.

Kondisi pengelolaan Taman Wisata Alam Baning tersebut jika tetap dibiarkan seperti sekarang maka proses degdrasi tetap berlangsung masif. Artinya seluruh aktivitas yang mengakibatkan kerusakan ekosistem gambut di Taman Wisata Alam Baning akan mengancam terjadinya perubahan ekosistem kawasan. Implikasinya ialah fungsi ekologis tanah gambut mengalami penurunan. Artinya dampak langsung dan tidak langsung dari degrdasi tanah gambut di Taman Wisata Alam Baning akan menimbulkan kerugian ekonomi, sosial, lingkungan yang besar bagi masyarakat.

Beberapa penelitian telah banyak di lakukan di kawasan
Taman Wisata Alam Baning khususnya yang terkait aspek keanekaragaman jenis flora, tumbuhan anggrek, tumbuhan pakan satwa kelasi dan keanekaragaman jenis rotan. Namun aspek keberlanjutan pengelolaan kawasan Taman Wisata Alam Baning sebagai ekosistem hutan rawa gambut belum pernah dilakukan. Penelitian terhadap keberlanjutan ekosistem hutan rawa gambut di kawasan Taman Wisata Alam Baning menjadi kebutuhan strategis untuk menjaga kelestarian fungsi Taman Wisata Alam Baning. Berkaitan dengan hal tersebut perlu dikaji pengelolaan Taman Wisata Alam Baning yang berorientasi keterpaduan dan keberlanjutan. Hasil kajian ini dapat dijadikan sebagai bahan pertimbangan ilmiah dalam memformulasikan kebijakan pengelolaan terpadu Taman Wisata Alam Baning dan berkelanjutan.

Memperhatikan kondisi Taman Wisata Alam Baning tersebut, maka penelitian ini dilakukan dengan tujuan untuk (1) menganalisis indeks dan status keberlanjutan pengelolaan kawasan Taman Wisata Alam 
Analisis Keberlanjutan Pengelolaan Ekowisata Ekosistem Hutan Rawa Gambut Pada Kawasan Taman Wisata Alam Baning

Baning dari dimensi ekologi, sosial, ekonomi dan institusional/ kelembagaan; (2) menganalisis atribut sensitif terhadap keberlanjutan pengelolaan kawasan Taman Wisata Alam Baning sebagai ekosistem hutan rawa gambut.

\section{METODELOGI PENELITIAN}

\section{Tempat dan waktu penelitian}

Penelitian ini dilakukan di Taman

Wisata Alam Baning Kabupaten

Sintang Provinsi Kalimantan

Barat. Taman Wisata Alam

Baning secara administratif berada di wilayah kota Sintang Kabupaten Sintang, memiliki luas sekitar 213 hektar, berada pada ketinggian $\pm 22 \mathrm{~m}$ di atas permukaan laut dan terletak di jantung kota Sintang. Taman Wisata Alam Baning secara ekologis tertetak di Daerah Aliran Sungai (DAS) Kapuas dan keberadaannya diapit oleh dua sungai besar, yaitu mencakup sungai Kapuas dan sungai Melawi. Waktu penelitian bulan JuniDesember 2017.

\section{Jenis dan Sumber Data}

Data yang diperlukan adalah data primer berupa atribut-atribut yang terkait dengan tiga dimensi keberlanjutan pengelolaan, yaitu: dimensi sosial ekonomi, ekologi dan institusional/kelembagaan. Data primer bersumber dari para responden dan pakar yang terpilih, serta hasil pengamatan langsung di lokasi penelitian. Sedangkan data sekunder diperoleh dari sumber kepustakaan dan dokumen beberapa instansi yang terkait dengan penelitian.

\section{Metode Pengumpulan Data}

Data sekunder diperoleh dari berbagai sumber antara lain dokumen statistik Kabupaten Sintang dalam Angka, dokumen perencanaan RTRW Kabupaten Sintang, Rencana Pengelolaan Jangka Panjang TWA Baning. Data primer diperoleh melalui pengamatan lapangan, wawancara dengan masyarakat dan tokoh masyarakat, aparat pemerintah dan triangulasi lapangan. Diskusi mendalam dilakukan dengan informan pakar mencakup 
Analisis Keberlanjutan Pengelolaan Ekowisata Ekosistem Hutan Rawa Gambut Pada Kawasan Taman Wisata Alam Baning

akademisi, lembaga swadaya masyarakat, aparat pemerintah (desa, kelurahan, kecamatan, kabupaten dan Balai Konservasi Sumberdaya Alam) dan tokoh masyarakat.

\section{Anallsis Data}

Analisis keberlanjutan pengelolaan Taman Wisata Alam Baning dilakukan dengan metode pendekatan Multi Dimensional Scaling (MDS). Analisis ini dilakukan melalui beberapa tahapan antara lain: Penentuan atribut berkeianjutan pengelolaan Taman Wisata Alam Baning menggunakan tiga dimensi keberlanjutan pengelolaan, yaitu: dimensi sosial ekonomi, ekologi dan institusional/kelembagaan.

Penilaian setiap atribut dalam skala ordinal berdasarkan kriteria keberlanjutan setiap dimensi. Penyusunan indeks dan status keberlanjutan.

Hasil skor dari setiap atribut dianalisis dengan multi dimensional scaling untuk menentukan titik yang mencerminkan posisi keberlanjutan terhadap dua titik acuan yaitu titik baik (good) dan titik buruk (bad). Skor perkiraan setiap dimensi dinyatakan dengan skala terburuk (bad) $0 \%$ sampai yang terbaik (good) $100 \%$. Adapun nilai skor yang merupakan nilai indeks keberlanjutan setiap dimensi dapat dilihat pada tabel berikut ini.

Tabel 1. Kategori Status Keberlanjutan.

\begin{tabular}{|l|l|l|l|}
\hline No. & Nilai Indeks Dimensi & Kategori & Keterangan \\
\hline 1 & $00,00-24,99$ & Buruk & Tidak berkelanjutan \\
\hline 2 & $25,00-49,99$ & Kurang & Kurang berkelanjutan \\
\hline 3 & $50,00-74,99$ & Cukup & Cukup berkelanjutan \\
\hline 4 & $75,00-100,00$ & Baik & Berkelanjutan \\
\hline
\end{tabular}

Sumber : Pitcher dan Preikshot (2001) 
Melalui metode MDS, maka posisi titik keberlanjutan dapat divisualisasikan melalui sebuah diagram dalam bentuk diagram layang-layang (kite diagram).

\section{HASIL DAN PEMBAHASAN}

\section{Status Keberlanjutan Dimensi} Ekologi

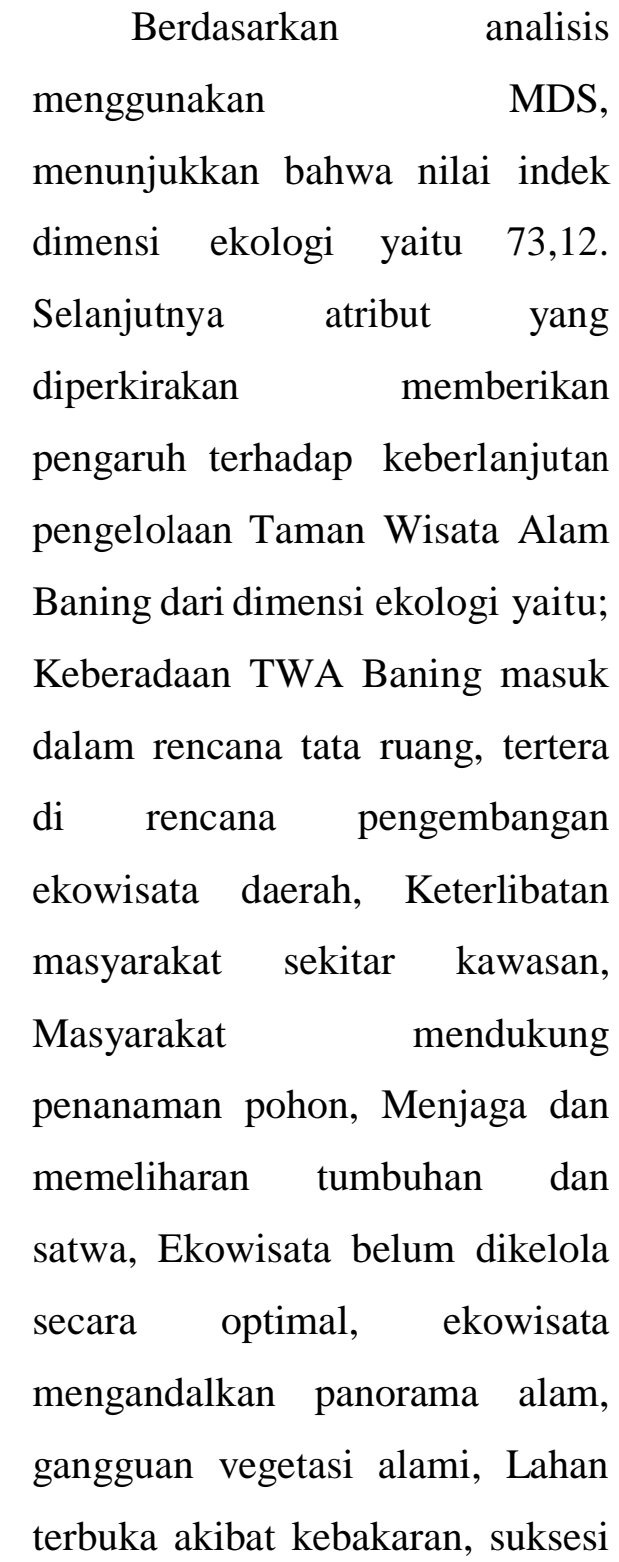

tumbuhan akibat pohon-pohon tumbang, Subsidensi tanah gambut mengakibatkan akar pohon menggantung, drainase mempengaruhi penurunan permukaan gambut, pengaturan tata air, pembangunan pintu air, penurunan permukaan gambut, akar pohon menggantung, lapisan gambut mengalami pendangkalan, hutan rawa gambut rapuh dan mudah terbakar, Jenis indikator pada tanah gambut: Ramin, Jelutung, Kantong Semar, Jenis fauna indikator hutan rawa gambut berupa Kelasi, kura-kura dan beberapa fauna lainnya, bila jenis tersebut hilang maka ekosisitem gambut terganggu atau mengalami kerusakan.

Analisis leverage dilakukan untuk melihat atribut-atribut yang sensitif memberikan pengaruh terhadap nilai indek keberlanjutan dimensi ekologi. Berdasarkan analisis leverage tersebut antara lain Lahan terbuka akibat kebakaran, tanah gambut mengalami penurunan sehingga mengakibatkan perakaran pohon menggantung, adanya drainase 
Analisis Keberlanjutan Pengelolaan Ekowisata Ekosistem Hutan Rawa Gambut Pada Kawasan Taman Wisata Alam Baning

$\begin{array}{lrrlrl}\text { disekeliling } & \text { kawasan yang } & & \text { dipengaruhi tingkat kematangan } \\ \text { mengakibatkan } & \text { penurunan } & \text { gambut dan kedalaman saluran } \\ \text { permukaan } & \text { gambut yang } & \text { drainase (Agus dan Subiksa, } \\ \text { mengakibatkan } & \text { pohon-pohon } & \text { 2008). }\end{array}$

banyak yang tumbang, tumbuhan mengalami suksesi akibat pohonpohon tumbang dan terjadi penurunan permukaan gambut dari waktu ke waktu.

Adanya pembuatan kanal di sekeliling kawasan telah mengakibatkan terjadinya penurunan permukaan gambut dan perakaran pohon menggantung, sehingga pohonpohon banyak yang tumbang dan mati. Subsiden tanah gambut disebabkan pengurangan kadar air, penyusutan volume akibat adanya proses dekomposisi dan erosi. Untuk mengatasi kehilangan air berlebihan dibuat pintu air yang berfungsi mengatur tata air. Drainase mengakibatkan penurunan permukaan gambut begitu cepat. Di Malaysia dilaporkan akibat drainse dalam dua tahun pertama laju subsiden bisa mencapai $50 \mathrm{~cm}$ dan pada tahun berikutnya laju subsiden sekitar 2-6 cm/tahun yang

\section{Status Keberlanjutan Dimensi Sosial Ekonomi}

Hasil analsis MDS terhadap dimensi sosial ekonomi keberlanjutan pengelolaan Taman Wisata Alam Baning menunjukkan bahwa nilai indek dimensi ekonomi ialah 55,08. Atribut yang diperkirakan memberikan pengaruh terhadap dimensi ini ialah; pendapatan dari pengelolaan wisata, sumber pendapatan tambahan, pembangunan sarana dan prasarana wisata, tersedianya sarana dan prasarana pendukung, akses jalan menuju Kawasan Wisata mudah, tersedianya kelembagaan ekonomi, Kelembagaan ekonomi berkaitan dengan pengelolaan ekowisata, Kelembagaan ekonomi sebagai penyedia modal usaha, terbukanya lapangan kerja, terbukanya kesemptan berusaha, pembuatan souvenir atau cindera mata, terbentuknya usaha di sektor jasa, 
peningkatan pendapatan

masyarakat, tingkat penghasilan dipengaruhi banyaknya kunjungan wisatawan, terpenuhinya

kebutuhan hidup layak, kegiatan wisata alam berkonstribusi terhadap peningkatan PAD, konstribusi perekonomian masyarakat terhadap PDRB meningkat, keuntungan yang diperoleh dari sektor jasa wisata mengalami peningkatan, keuntungan finansial dan keuntungan jasa lingkungan, muncul konflik tata batas, konflik dipicu oleh penyerobotan batas kawasan, konflik dipicu oleh penertiban usaha di sekitar kawasan, tingkat ketergantungan masyarakat terhadap kawasan wisata cukup tinggi, keterlibatan masyarakat dalam perencanaan, pelaksanaan dan evaluasi.

Analisis leverage dilakukan untuk melihat atribut-atribut yang sensitif terhadap keberlanjutan pengelolaan Taman Wisata Alam Baning pada dimensi sosial ekonomi. Atribut-atribut yang sensitif terhadap keberlanjutan pengelolaan Taman Wisata Alam
Baning pada dimensi sosial ekonomi, yaitu: munculnya konflik antara KSDA dengan masyarakat di sekitar kawasan, konflik dipicu oleh penyerobotan batas kawasan, konflik dipicu oleh penertiban usaha di sekitar kawasan, keterlibatan masyarakat dalam perencanaan, pelaksanaan dan evaluasi, keuntungan berupa finansial dan jasa lingkungan. Artinya dimensi sosial ekonomi dapat dioptimalkan dengan melakukan pengelolaan atribut yang sensitif. Tingginya intensitas sosial ekonomi kedepannya bisa digeser dengan mengoptimalkan potensi ekowisata yang memberikan manfaat besar kepada masyarakat. Hal tersebut penting untuk mengurangi beban ekologis akibat tekanan pembangunan, seperti pembuatan drainase. Oleh karena itu pengembangan ekowisata berbasis ekosistem hutan rawa gambut diharapkan mampu meningkatkan perekonomian masyarkat karena terbukanya lapangan kerja dan kesempatan berusa. Terbatasnya perhatian pemerintah terhadap 
sektor wisata berbasis ekosistem hutan rawa gambut di kawasan Taman Wisata Alam Baning merupakan salah satu faktor masih relatif kecilnya nilai ekonomi yang diperoleh masyarakat. Status Keberlanjutan Dimensi Sosial ekonomi berdasarkan analisis menggunakan MDS adalah 55,08 atau cukup berkelanjutan.

\section{Status}

Keberlanjutan

\section{Dimensi}

\section{Institusional/Kelembagaan}

Dimensi kelembagaan untuk keberlanjutan pengelolaan Taman Wisata Alam Baning indeks keberlanjutannya adalah 51,42. Atribut yang diperkirakan memiliki pengaruh terhadap dimensi kelembagaan ialah: kebijakan selalu disosialisasikan kepada masyarakat, pembuatan kebijakan melibatkan masyarakat sekitar kawasan, penyuluhan tentang tata batas kawasan kepada masyarakat, melakukan Penyuluhan pentingnya menjaga flora dan fauna, larangan mengambil dan/atau tumbuhan maupun satwa dalam Kawasan, dibentuk lembaga pengawas lokal, anggota lembaga pengawas lokal dari setiap RT terdekat, Lembaga pengawas lokal bekerja berdasarkan petunjuk Balai KSDA Kalimantan Barat, keterlibatan aktif lembaga lokal dalam mendukung wisata berkelanjutan, pembinaan lembaga formal maupun informal dalam mendukung ekowisata, melatih pengurus lembaga lokal dalam pelayanan wisata, melakukan studi banding, kemudahan akses informasi, setiap wisatawan berkunjung terlayani dengan baik, ketersediaan infrastruktur pendukung, kemudahan akses jalan dan ketersediaan transportasi menuju kawasan dan tersedianya peralatan pengamatan satwa.

Hasil analisis leverage terhadap atribut-atribut di atas menunjukkan beberapa atribut yang memiliki sensitivitas tinggi terhadap dimensi institusional/ kelembagaan yaitu: Melakukan penyuluhan tentang pentingnya menjaga dan melestarikan flora 
Analisis Keberlanjutan Pengelolaan Ekowisata Ekosistem Hutan Rawa Gambut Pada Kawasan Taman Wisata Alam Baning

dan fauna, kemudahan akses jalan dan ketersediaan transportasi menuju kawasan, pengawas lokal diambil dari RT terdekat dengan kawasan wisata, pembentukan lembaga pengawas lokal, lembaga pengawas lokal bekerja berdasarkan petunjuk Balai KSDA Kalimantan Barat.

Kebijakan pengelolaan Taman Wisata Alam Baning belum memiliki mekanisme lintas sektor diantara sektor-sektor terkait. Masing-masing sektor bergerak dengan program kerjanya dan mengabaikan keterpaduan. Hal tersebut berimplikasi pada lemahnya koordinasi antar sektor untuk program kerja yang akan dilakasanakan di Taman Wisata Alam Baning. Hal tersebut juga didukung oleh kondisi dimana belum ada kelembagaan khusus tentang pengelolaan ekowisata Taman Wisata Alam Baning. Sehingga kebijakan yang dihasilkan belum sinergi dan forum konservasi belum optimal dalam mendukung peran-peran pendampingannya. Dalam rangka pengelolaan terpadu dan berkelanjutan, penting dibuat mekanisme lintas sektor untuk mengkoordinasikan berbagai program yang akan dilaksanakan di Taman Wisata Alam Baning atau program yang dapat berdampak terhadap kelestarian ekosistem hutan rawa gambut. Disamping itu kelembagaan khsusus untuk ekowisata adalah penting untuk mengkoordinasikan berbagai sektor yang memiliki keterkaitan dengan Taman Wisata Alam Baning.

Kombinasi dari ketiga dimensi yang digunakan untuk mengukur nilai indeks keberlanjutan pengelolaan ekowisata hutan rawa gambut pada Kawasan Taman Wisata Alam Baning di tunjukkan oleh gambar berikut. 


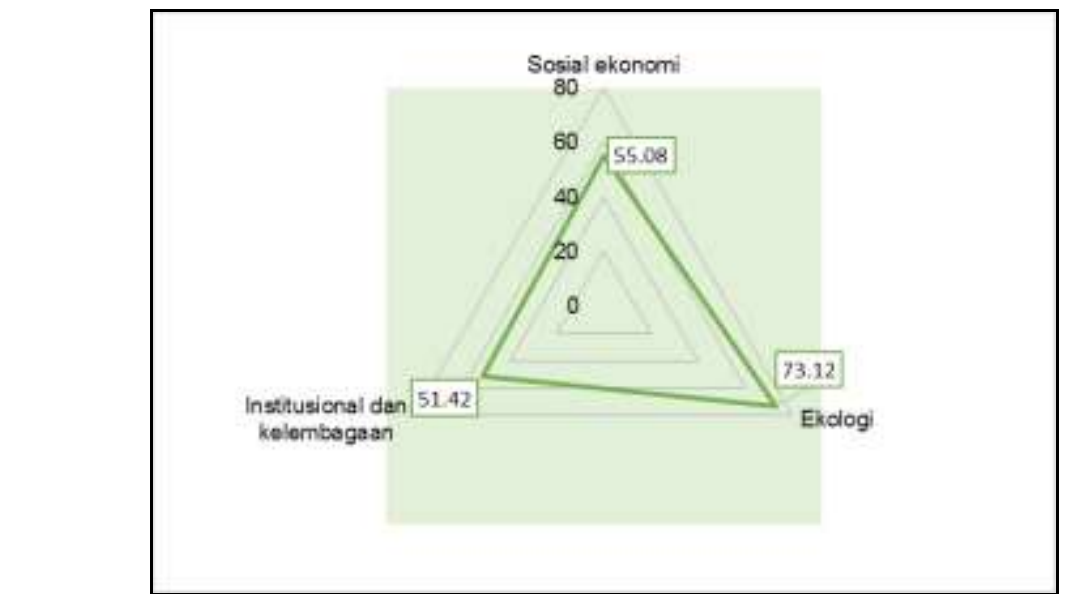

Gambar 1. Diagram Layang-layang Status Keberlanjutan Keseluruhan Sumber: Data primer diolah, 2017

Secara rata-rata, nilai indeks keberlanjutan ini sebesar 59.87 atau berada pada selang 50.00 - 74.99 (cukup berkelanjutan). Dimensi yang paling unggul dalam hal keberlanjutannya adalah dimensi ekologi, sedangkan dimensi yang memiliki indeks keberlanjutan paling rendah adalah sosial ekonomi. Oleh karena itu, masalah sosial ekonomi secara khusus perlu mendapat perhatian yang lebih serius agar program ekowisata pada Kawasan Taman Wisata Alam Baning bisa berjalan secara berkelanjutan.

\section{KESIMPULAN}

Atribut yang memiliki sensitivitas tinggi terhadap keberlanjutan pengelolaan ekowisata hutan rawa gambut pada kawasan Taman
Wisata Alam Baning ada 15 atribut. Nilai tertinggi sensitivitas atribut dimasing-masing dimensi ialah : lahan terbuka akibat kebakaran (dimensi ekologi), adanya konflik antara pihak pemerintah (KSDA) dengan masyarakat di sekitar kawasan (Sosial ekonomi), melakukan penyuluhan tentang pentingnya menjaga dan melestarikan flora dan fauna yang ada dalam Kawasan TWA Baning (institusional/kelembagaan).

\section{DAFTAR PUSTAKA}

Agus, F., dan Subiksa, IGM. 2008. Lahan Gambut: Potensi Untuk Pertanian dan Aspek Lingkungan. Balai Penelitian Tanah. Bogor.

Andriesse, J.P. 1988. Nature and Management of Tropical 
Peat Soils. FAO Soils Bulletin 59. Food and Agriculture Organization of The United Nations. Rome. $165 \mathrm{p}$.

Ashton P.S. 2009. Conservation of Borneo biodiversity: do small lowland parks have a role, or are big inland sanctuaries sufficient? Brunei as an example. Biodiversity and Conservation: P 1. 343-356.

Bappedal. 2001. Kriteria Pengembangan Ekowisata dalam rangka Pengendalian Kerusakan

Keanekaragaman Hayati di Taman Nasional dan Taman Wisata.

Badan Pengendalian Dampak Lingkungan.

Bismark M. 2014. Model pengelolaan Kawasan Konservasi Berbasis Ekosistem, Jakarta. Indonesia.

Catherine M. Y and Lalita N. Gomez. 2009. Leaf Litter Decomposition In A Tropical Peat Swamp Forest In Peninsular Malaysia. Wetland Ecol Manage. 17: 231-241.

Fauzi, A. 2013. Analisis Keberlanjutan melalui Rapid Aprraisal dan Multidimensional Scaling $(R A P+M D S)$. Bogor (ID): Program Studi Pengelolaan Sumberdaya Alam dan
Lingkungan, Institut Pertanian Bogor.

Leila, K., Ngudiantoro, M.F., and A. Halim. 2013. Controlling $\mathrm{CO} 2$ and $\mathrm{CH} 4$ Emission in a Degraded Peat Swamp Forest Related to Water Table and Peat Characteristics. Applied Mechanics and Materials: pp 202-206.

Marita, I. 2005. Institutional Transformation for Better Policy Implementation and Forcemenl in Resosudarmo (edt): The Politics and Economics of Indonesia's Natural Resources. SEAS, Singapore.291 hal.

Wosten, J.H.M., Ismail, A.B., and van Wijk, A.L.M. 1997. Peat subsidence and its practical implications: a case study in Malaysia. Geoderma 78:25-36.

Wosten JHM, et al. 2006. Interrelationships between hydrology and ecology in fire degraded tropical peat swamp forests. International Journal of Water Resources Development 22: 157-174.

Yule CM. 2010. Loss of biodiversity and ecosystem functioning in Indo-Malayan peat swamp forests. Biodiversity and Conservation 19: 393409. 
